\title{
Selected Properties of Mahogany Wood Flour Filled Polypropylene Composites: The Effect of Maleic Anhydride-Grafted Polypropylene (MAPP)
}

\begin{abstract}
Vedat Çavuş*
The aim of this study was to produce mahogany (Swietenia macrophylla) wood flour filled polypropylene (both recycled and virgin) composites and to determine the effects of maleic anhydride-grafted polypropylene (MAPP) on the interfacial compatibility, density, and other mechanical properties of the resulting composites. Approximately $40 \mathrm{wt} \%$ of mahogany wood flour, and $60 \mathrm{wt} \%$ of polypropylene, $3 \mathrm{wt} \%$ of MAPP, 1.5 wt $\%$ of zinc stearate, and 1.5 wt\% of wax were used during composite manufacturing. Test specimens were manufactured using extrusion and injection molding processes. The flexural, tensile, impact, and hardness properties of all specimens were determined. Scanning electron microscopy was used to study the morphology and interfacial compatibility of the filler in prepared composites. The test results showed that MAPP use and the filler rates affected the density and mechanical properties of test specimens.
\end{abstract}

Keywords: Recycled and virgin polypropylene; MAPP; Filler rates; Mechanical properties; Mahogany wood flour

Contact information: Izmir Katip Celebi University, Forest Faculty, Forest Industry Engineering, Izmir, Turkey; *Corresponding author: vedat.cavus@ikcu.edu.tr

\section{INTRODUCTION}

Big leaf mahogany (Swietenia macrophylla) belonging to the family of Meliaceae is one of the most commercially important timber tree species in neo-tropical forests. It is naturally grown from southern Mexico to the southern Amazon basin of Bolivia, Brazil, and Peru (Anoop et al. 2014). Mahogany wood with the density of $0.55 \mathrm{~g} / \mathrm{cm}^{3}$ is used for various purposes including furniture, paneling, parquet and doors, buildings, interior and exterior, aircraft, wagon, small ship, violin making, marquetry, turning, engraving, etc. (Bozkurt and Erdin 1998; Lemmens 2005; Sharmin et al. 2015). During the conversion of the mahogany wood material from the logs to the desired shapes and sizes, a lot of waste is produced. The amount of waste varies according to the number of cuts, the number of operations performed, and the thickness of the cutter.

Wood plastic composites (WPC) consist of wood fibers or flours (WF) and polymers. WPC is manufactured with specific heat and pressure conditions with extruder and injection machines. The WF can be generated from various sources of fiber or flour. Polymers used are either in virgin or recycled form. Currently, the main applications of WPC products are cladding, decking, fencing, paneling, and furniture (Çetin et al. 2014; Özmen et al. 2014; Çavuş and Mengeloğlu 2016; Martikka and Karki 2019; Mengeloğlu and Çavuş 2019). Good adhesion of matrix with WF improves the mechanical properties of WPCs. Unfortunately, both components are naturally incompatible due to the hydrophilic nature of wood materials and hydrophobic nature of polymers. By using either physical or chemical modification, compatibility of the polymer matrix and WF in 
composites is improved. Compatibilizer/coupling agents can also considerably improve the performance of WPC (Klyosov 2007; Kim and Pal 2011). The preferred coupling agents for polyolefin are maleic anhydride-grafted polyethylene (MAPE) or propylene (MAPP).

During WPC production, the anhydride of the maleated polyolefins (MAPP or MAPE) reacts with hydroxyl groups on wood surface to form ester linkages. While the maleated ends of MAPP/MAPE bond to WF, the polyolefin side of the coupling agent interacts with the melted thermoplastic matrix, producing a bond between the hydrophilic WF and hydrophobic thermoplastic (Kattas et al. 2000; Rowell 2006; Yang et al. 2007). In actual production units, to improve the ease of processing and interfacial compatibility of WPCs, some lubricants, compatibilizer, or coupling agents are used during compounding. The addition of an internal lubricant is effective in reducing the apparent viscosity at high WF loadings. The apparent shear viscosity of the WPC melts decreases gradually with increased lubricant content (Li et al. 2004; Adhikary et al. 2011; Mengeloğlu and Çavuş 2019).

In this study, the effect of MAPP on the density and some mechanical properties of polypropylene (PP) composites were determined.

\section{EXPERIMENTAL}

\section{Materials}

Mahogany wood flour (WF) was used as a lignocellulosic filler. Mahogany flour was supplied by Yatch factory (İzmir, Turkey). Polypropylene (MH 418; density 0.905 $\mathrm{g} / \mathrm{cm}^{3}$, MFI $4.5 \mathrm{~g} / 10 \mathrm{~min}$, melting point $163^{\circ} \mathrm{C}$ ) was obtained from Petkim Petrochemical Co. (Turkey). Recycled polypropylene (rPP) was purchased from seller in Izmir (Turkey). Paraffin wax (K.130.1000) was used as a lubricant (softening point $56{ }^{\circ} \mathrm{C}$ to $58{ }^{\circ} \mathrm{C}$, density $0.93 \mathrm{~g} / \mathrm{cm}^{3}$ ). Zinc stearate, a lubricant and mold discharging agent, (white powder, melting point $130{ }^{\circ} \mathrm{C}$, density $1.1 \mathrm{~g} / \mathrm{cm}^{3}$ ) and MAPP (Licomont AR 504 by Clariant) were utilized as coupling agents (softening point $156^{\circ} \mathrm{C}$, density $0.91 \mathrm{~g} / \mathrm{cm}^{3}$ ) for improved performances of WPCs.

\section{Methods}

The mahogany wood particles were turned into flour form using a Wiley mill. These flours were classified as 40-60-80-100 to 200 mesh sizes. Mahogany WF passing through 60 mesh screen and staying on 80-mesh screen were used. The WF was dried in an oven for $24 \mathrm{~h}$ at $103 \pm 2{ }^{\circ} \mathrm{C}$ ). The moisture content of dried WF was below $1 \%$.

The procedure for the manufacturing is given in Table 1. Depending on the method, WF, PP, rPP, MAPP, and wax were mixed in a high intensity mixer (900 to $1000 \mathrm{rpm}$ in 2 s) to supply a homogeneous blend. These blends were compounded in a single-screw extruder at $40 \mathrm{rpm}$ screw speed in the temperatures range of $170-180-185-190$ to $200{ }^{\circ} \mathrm{C}$ (from barrel to die). The extruded compounds were first cooled in a water pool $\left(23{ }^{\circ} \mathrm{C} \pm 2\right.$ ${ }^{\circ} \mathrm{C}$ ). Cooled extruded compounds were granulated into pellets by Wiley mill. The pellets were dried in oven at $103 \pm 2{ }^{\circ} \mathrm{C}$ ) for $24 \mathrm{~h}$. The moisture content of pellets was reduced below $1 \%$ before the injection molding. The injection-molding machine (HAIDA HDX88 , Ningbo, China) was used for manufacturing specimens. Injection pressure was set as 5 to $6 \mathrm{MPa}$. The temperatures of machine were set as $180{ }^{\circ} \mathrm{C}$ to $200{ }^{\circ} \mathrm{C}$ from feed zone to die zone. 
Table 1. Manufacturing Compositions

\begin{tabular}{|c|c|c|c|c|c|c|c|}
\hline No & ID & PT & PR (\%) & WF (\%) & MAPP (\%) & Wax (g) & Zn (g) \\
\hline 1 & PP-0-0 & PP & 100 & 0 & 0 & 1.5 & 1.5 \\
\hline 2 & PP-20-0 & PP & 80 & 20 & 0 & 1.5 & 1.5 \\
\hline 3 & PP-40-0 & PP & 60 & 40 & 0 & 1.5 & 1.5 \\
\hline 4 & PP-0-3 & PP & 100 & 0 & 3 & 1.5 & 1.5 \\
\hline 5 & PP-20-3 & PP & 80 & 20 & 3 & 1.5 & 1.5 \\
\hline 6 & PP-40-3 & PP & 60 & 40 & 3 & 1.5 & 1.5 \\
\hline 7 & rPP-0-0 & rPP & 100 & 0 & 0 & 1.5 & 1.5 \\
\hline 8 & rPP-20-0 & rPP & 80 & 20 & 0 & 1.5 & 1.5 \\
\hline 9 & rPP-40-0 & rPP & 60 & 40 & 0 & 1.5 & 1.5 \\
\hline 10 & rPP-0-3 & rPP & 100 & 0 & 3 & 1.5 & 1.5 \\
\hline 11 & rPP-20-3 & rPP & 80 & 20 & 3 & 1.5 & 1.5 \\
\hline 12 & rPP-40-3 & rPP & 60 & 40 & 3 & 1.5 & 1.5 \\
\hline
\end{tabular}

PT: Polymer type; PR: Polymer rate; WF: Wood Filler; Zn: Zinc stearate $\left(\mathrm{C}_{36} \mathrm{H}_{70} \mathrm{O}_{4} \mathrm{Zn}\right)$.

Test specimens were first conditioned at room temperature $\left(23 \pm 2{ }^{\circ} \mathrm{C}\right)$ and $65 \pm$ $2 \%$ relative humidity. The density was determined by a water displacement technique according to the ASTM D792 (2007) standard. Flexural, tensile, impact properties, and hardness of all specimens were determined according to ASTM D790 (2003), ASTM D638 (2001), ASTM D256 (2000), and ASTM D2240 (2010), respectively. Flexural and tensile testing were implemented on Zwick $10 \mathrm{KN}$ (Ulm, Germany), while a HIT5, 5P (Zwick) was used for impact property testing on notched specimens. The notch was added using a RayRan $^{\text {TM }}$ Polytest notching cutter (London, UK). For statistical analysis, Design-Expert ${ }^{\circledR}$ version 7.0.3 statistical software (Minneapolis, USA) was used. Scanning electron microscopy (SEM) was used to determine the morphological properties of produced samples. They were dipped in to liquid nitrogen and snapped in half to attain clean surfaces. Before taking images at $20 \mathrm{kV}$ and $100 \mathrm{X}$ magnification, the fractured surfaces were sputtered with gold.

\section{RESULTS AND DISCUSSION}

The effect of WF rates and MAPP use on the density and some mechanical properties of PP- and rPP-based composites were studied. The density, tensile strength (TS), tensile modulus (TM), elongation at break (EatB), flexural strength (FS), flexural modulus (FM), impact strength (IS), and hardness $(\mathrm{H})$ values were determined. The densities of PP and rPP specimens were in the range of $0.884 \mathrm{~g} / \mathrm{cm}^{3}$ to $1.04 \mathrm{~g} / \mathrm{cm}^{3}$ and 0.90 $\mathrm{g} / \mathrm{cm}^{3}$ to $1.02 \mathrm{~g} / \mathrm{cm}^{3}$, respectively. The density values are presented in Fig. 1. Statistical analysis showed that WF rates had significant effect on density $(\mathrm{P}<0.0001)$. This increase was believed to be due to the higher cell wall density of lignocellulosic materials (Mengeloğlu and Karakuş 2012; Karakuş and Mengeloğlu 2016). This was because the density of the wood substance in the cell wall is about $1.5 \mathrm{~g} / \mathrm{cm}^{3}$ (Mäkinen et al. 2002). The bulk density of wood flour depends on factors such as moisture content, particle size, and species (Clemons 2010). The MAPP use also had an effect on densities but this effect was less pronounced compared to WF content $(\mathrm{P}=0.0303)$. It should be noted that the effect of MAPP on density was more obvious at high WF content (40\%). Polymer type (PT), on the other hand, had no significant effect on densities. Thus, both PP and rPP composites provided similar results $(\mathrm{P}=0.5999)$. 


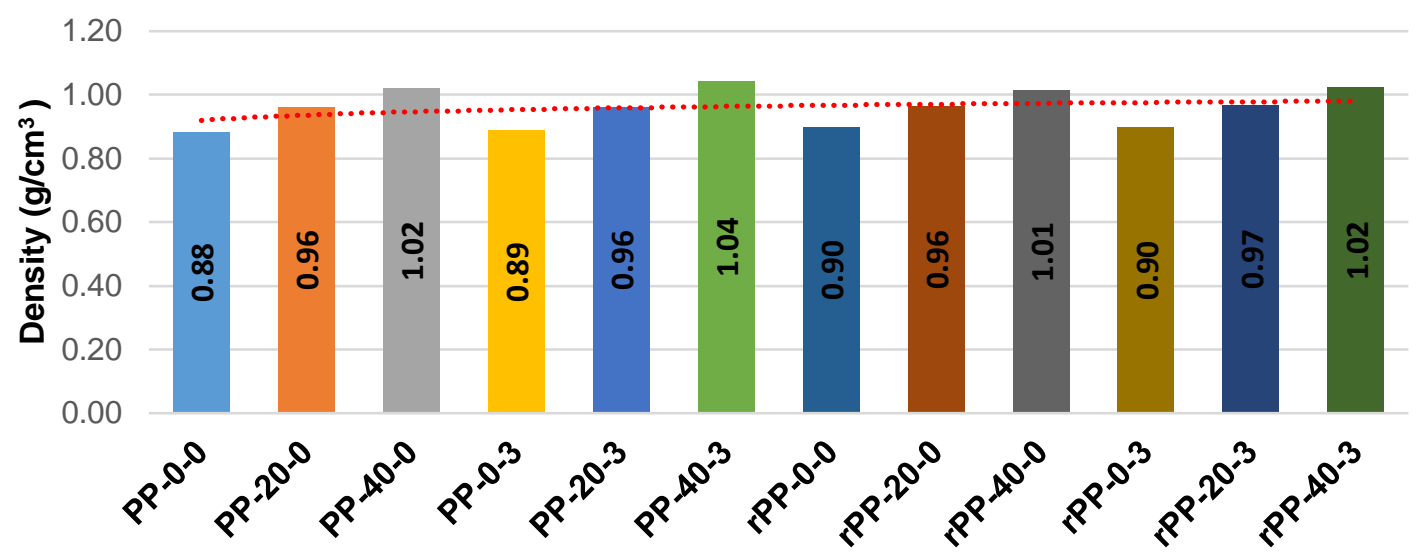

Fig. 1. Densities of manufactured PP and rPP composites 0 and $3 \%$ MAPP

The tensile strength values are presented in Fig. 2. The TS of PP and rPP specimens were in range of 18.7 MPa to 28.7 MPa and 19.0 MPa to 27.6 MPa, respectively. Statistical analysis showed that the WF rates were significantly important for TS $(\mathrm{P}<0.0001)$. Regardless of having MAPP or PT, the TS values were reduced with increased concentration of WF. The usage of MAPP also had significant effect on TS of the composites $(\mathrm{P}<0.0001)$. Both rPP and PP composites provided significantly higher TS values compared to composites having no MAPP in the formulations. This improvement was more pronounced in rPP based specimens. Statistical analysis showed that PT also had a significant effect on TS ( $\mathrm{P}<0.0001)$. The PP composites provided better TS than recycled ones, especially when MAPP was included in the formulation. The molecular chain length of PP might be reduced during recycling process, resulting in weaker properties.

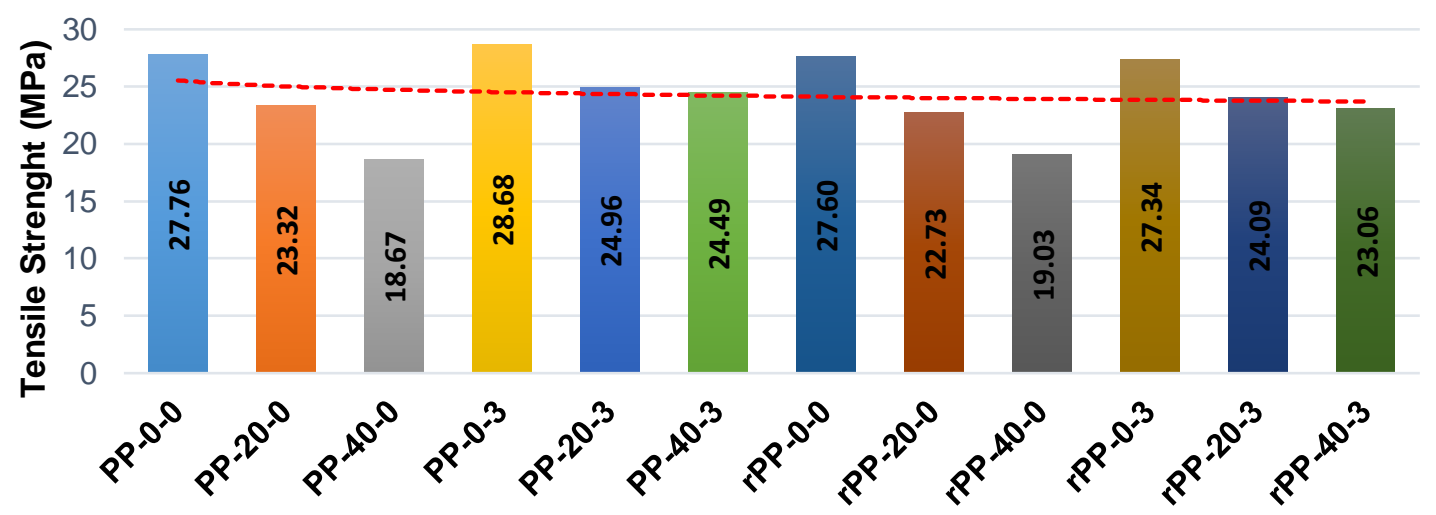

Fig. 2. Tensile strength of manufactured PP and rPP composites 0 and $3 \%$ MAPP

The morphology of the samples was studied using scanning electron microscopy (SEM) (Fig. 3). There were more holes caused by pulled out fibers and standing fibers in samples with no MAPP in the formulations. The rPP composites had more holes than the PP composites. After using 3\% MAPP coupling agent, the number of holes and standing fibers were considerably reduced because of the improved adhesion between the polymer and WF. In previous studies (Clemons 2010; Lopez et al. 2012), MAPP composites have shown higher mechanical properties because MAPP minimizes the creation of microcracks between the dissimilar polar WF and non-polar PP matrix. 

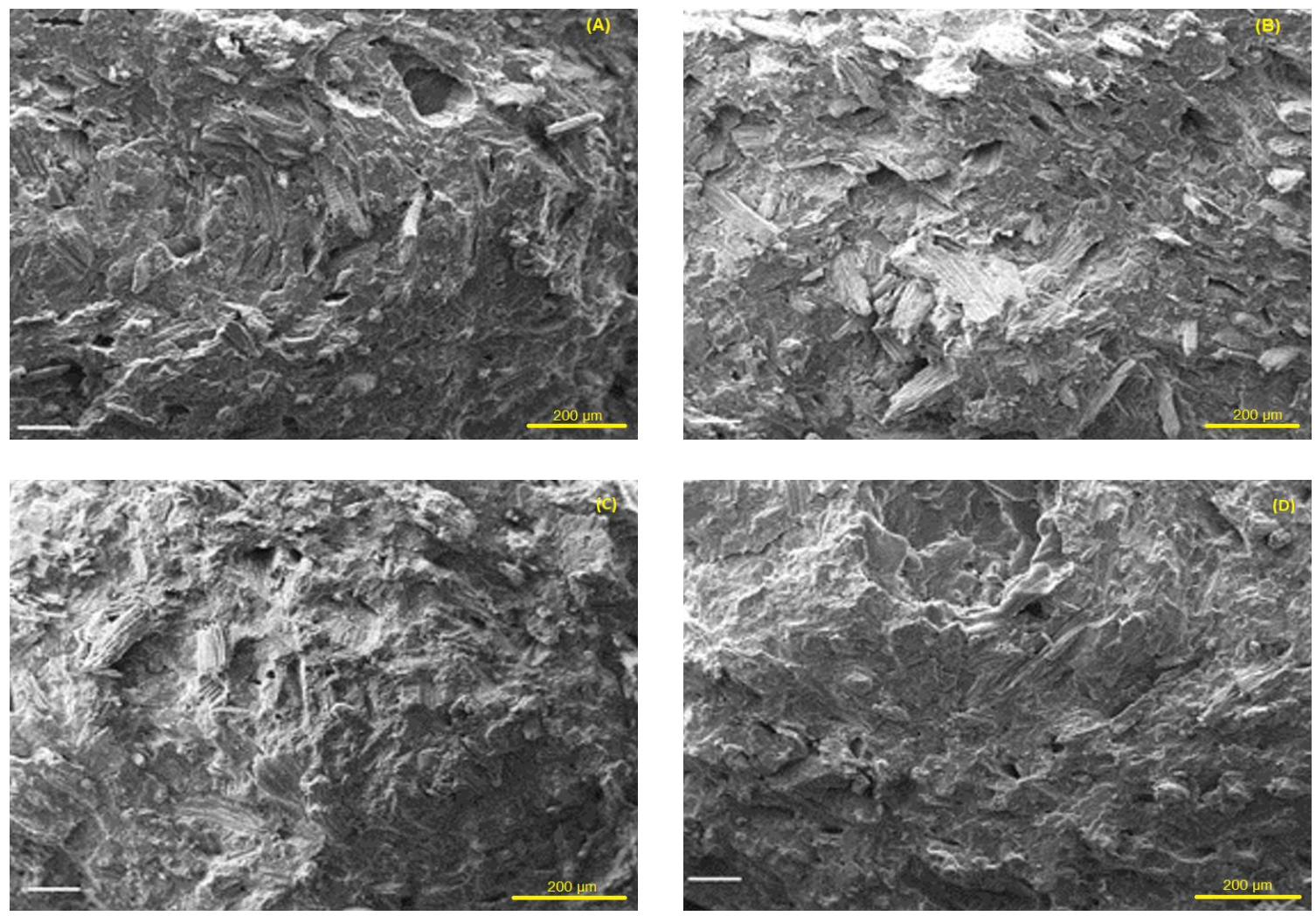

Fig. 3. SEM images of the manufactured composites; (A): PP-40-0; (B): rPP-40-0; (C): PP-40-3; (D): rPP-40-3

The TM of PP and rPP values were in the range of $453 \mathrm{MPa}$ to $826 \mathrm{MPa}$ and 503 $\mathrm{MPa}$ to $865 \mathrm{MPa}$, respectively. Figure 4 shows the TM values of test specimens. Statistical analysis showed that the WF amounts significantly affected the TM values $(\mathrm{P}<0.0001)$. Regardless of PT and MAPP use, the TM values were increased with the rising concentration of WF.

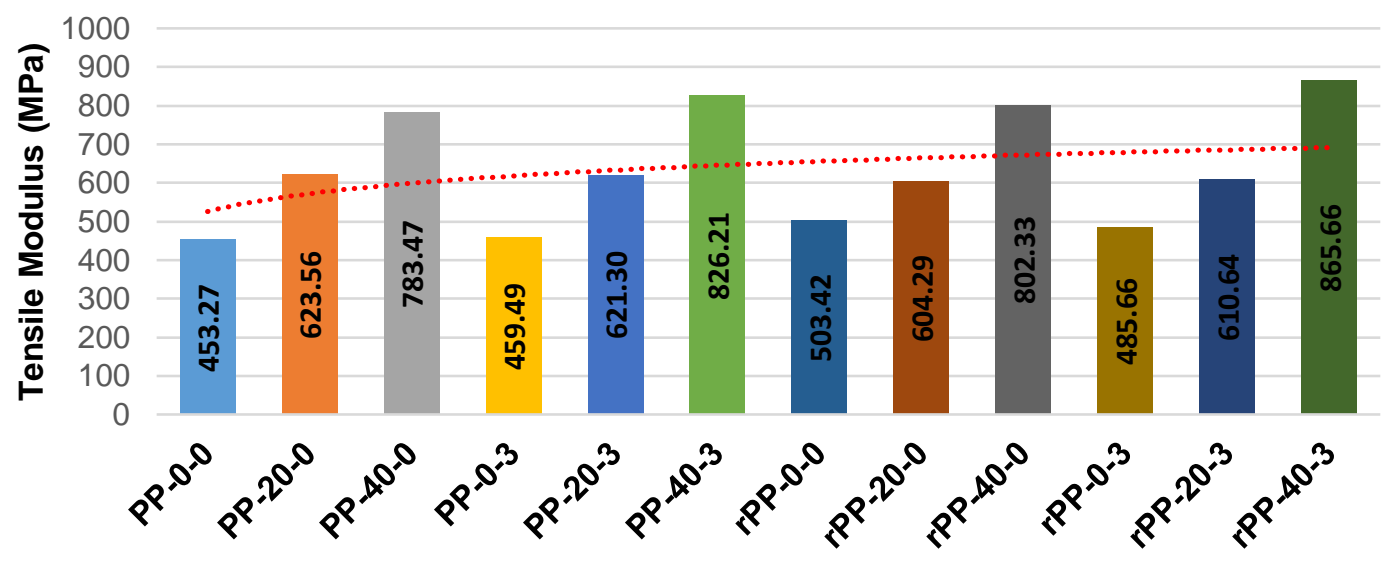

Fig. 4. Tensile modulus of manufactured PP and rPP composites 0 and $3 \%$ MAPP

The WF indicated higher modulus when compared to polymer matrix; as a result, their mixture showed modulus values higher than the polymer itself (Matuana et al. 1998; 
Clemons 2010; Mengeloğlu et al. 2015). The MAPP content had a significant effect on TM of the composites $(\mathrm{P}=0.0155)$. This improvement was more pronounced at high concentrations of WF.

The EatB values of PP- and rPP-based composites were in the range of $3.88 \%$ to $452.8 \%$ and $3.88 \%$ to $454 \%$, respectively. The EatB values are presented in Fig. 5. Statistical analysis showed that the WF rates had a significant effect on EatB $(\mathrm{P}<0.0001)$. Regardless of having MAPP or PT, the EatB values were reduced with increasing concentration of WF. The MAPP use also had a significant effect on EatB of the composites $(\mathrm{P}<0.0001)$. Both rPP and PP composites provided significantly lower EatB values compared with composites having no MAPP in the formulations. Polymer composites became stiffer when the amount of WF in the matrix was increased. As a result, the EatB values were reduced. The EatB values are usually reduced with the increased modulus of the composites having WF, as reported for composites produced with various wood flours (Li and Matuana 2003; Mengeloğlu and Karakuş 2008).

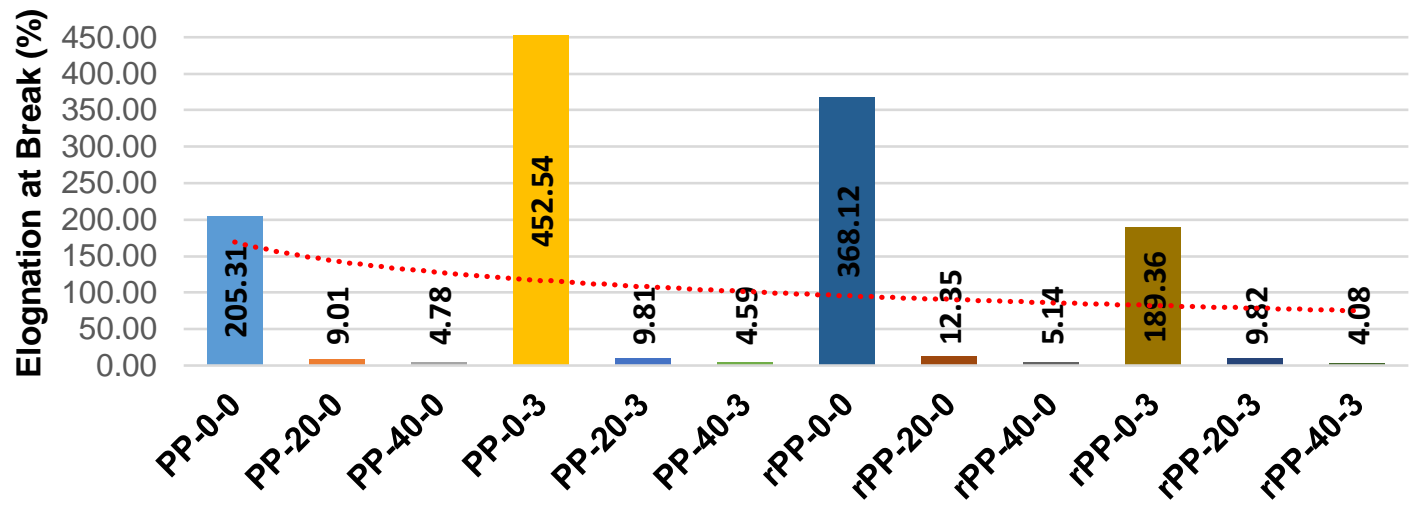

Fig. 5. Elongation at break of manufactured PP and rPP composites 0-3\% MAPP

The FS values of PP- and rPP-based composites were in the range of 33.0 to 42.3 $\mathrm{MPa}$ and 32.4 to $40.9 \mathrm{MPa}$, respectively. Figure 6 presents FS values of the test specimens. Statistical analysis showed that WF rates had a significant effect on FS (P<0.0001). Although addition of $20 \%$ WF showed some increase, FS decreased with $40 \% \mathrm{WF}$ in composites without MAPP coupling agent. However, in composites with MAPP coupling agents, both PP- and rPP-based composites provided higher FS with increased WF content.

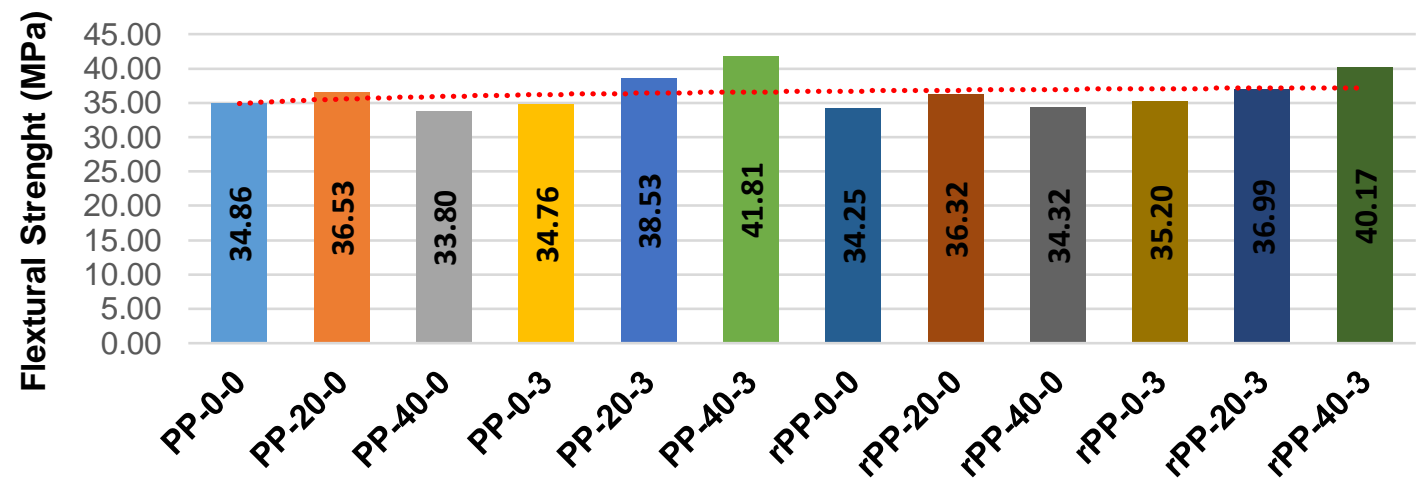

Fig. 6. Flexural strength manufactured of PP and rPP composites $0-3 \%$ MAPP 
The MAPP use had significant effect on FS of the composites $(\mathrm{P}<0.0001)$. Statistical analysis also showed that PT also had a significant effect on TS $(\mathrm{P}<0.0001)$. The PP composites provided higher FS compared to recycled ones especially for formulation having MAPP in it.

The FM values of PP- and rPP-based composites were in the range of 996.5 to 2309 MPa and 1026 to $2260 \mathrm{MPa}$, respectively. The FM are presented in Fig. 7. Similar to the FS, FM was significantly affected by WF rates $(\mathrm{P}<0.0001)$. The FM values showed improvement with WF, regardless of PT. The WF had higher modulus values than polymer (Bouafif 2009; Chaharmahali et al. 2010). The resulting composites of WF and polymer provide higher modulus values than the polymer itself (Clemons 2010; Lopez et al. 2012; Mengeloğlu et al. 2015).

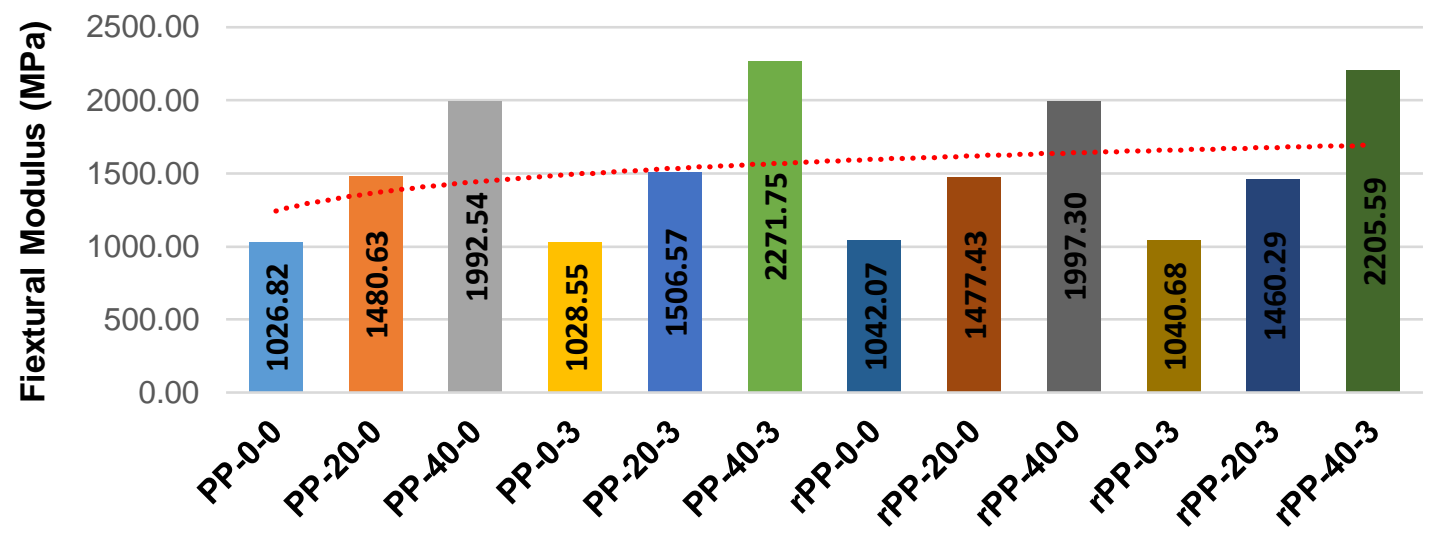

Fig. 7. Flexural modulus of manufactured PP and rPP composites 0 and $3 \%$ MAPP

The hardness values (Fig. 8) of PP- and rPP-based composites were in the range of 59.4 to 75.1 (Shore D) and 63.3 to 75.6 (Shore D), respectively. Statistical analysis showed that WF rate and MAPP use had significant effect on $\mathrm{H}$ values $(\mathrm{P}<0.0001)$. The effect of WF on $\mathrm{H}$ values was more pronounced than that of composites with MAPP. The PT on the other hand had no significant effect on $\mathrm{H}$ values. For the material characterization standpoint, the hardness values of all manufactured composites provided Shore D values of around 60 and above, which are classified as "extra hard" material. Ibach and Rowell (2013) showed that a higher polymer loading yields a higher WPC hardness.

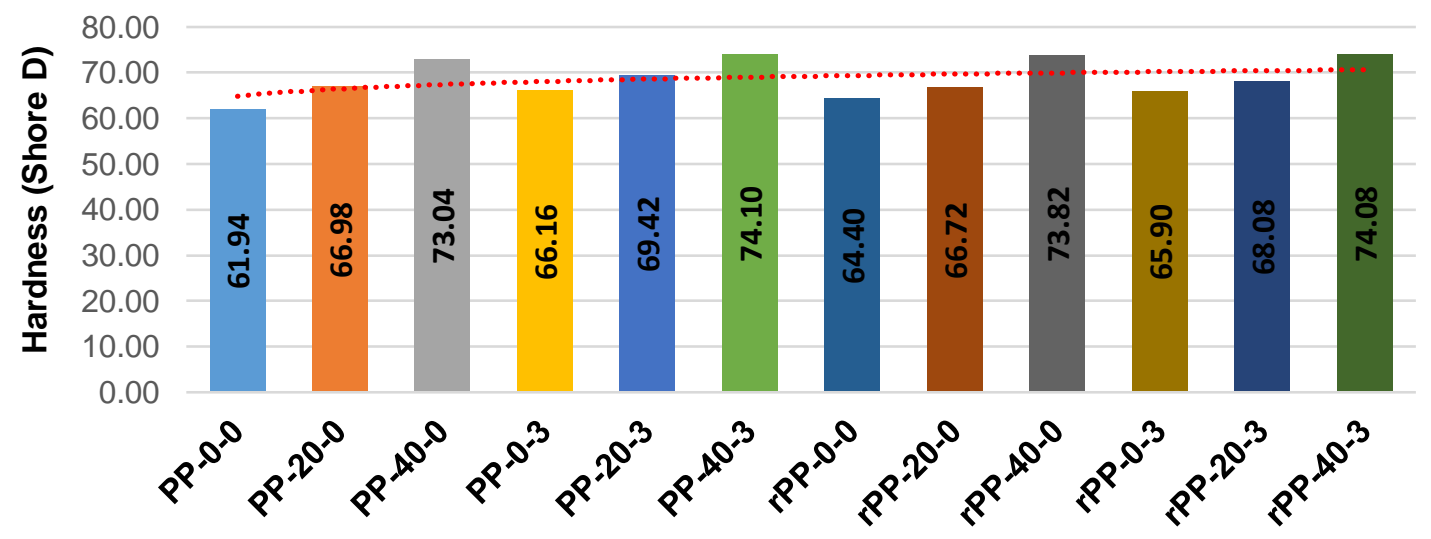

Fig. 8. Hardness properties of manufactured PP and rPP composites 0 and $3 \%$ MAPP 
In the case of IS, manufactured PP- and rPP-based composites provided values in the range of $1.41 \mathrm{~kJ} / \mathrm{m}^{2}$ to $2.03 \mathrm{~kJ} / \mathrm{m}^{2}$ and $1.26 \mathrm{~kJ} / \mathrm{m}^{2}$ to $2.13 \mathrm{~kJ} / \mathrm{m}^{2}$, respectively. The notched IS are presented in Fig. 9. There were some differences on IS values of composites; however, statistical analysis showed that these differences were not significant for the factors $\mathrm{PT}(\mathrm{P}=0.2117)$, WF amount $(\mathrm{P}=0.6242)$, and MAPP presence $(\mathrm{P}=0.7636)$.

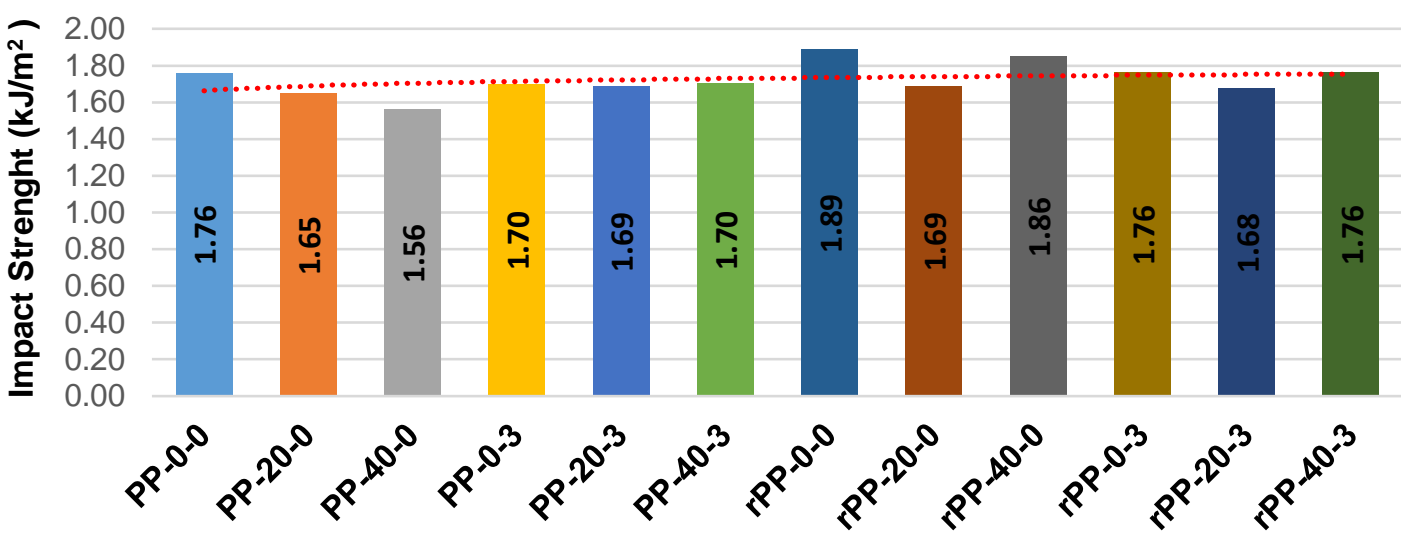

Fig. 9. Impact strength properties of manufactured PP and rPP composites 0 and $3 \%$ MAPP

\section{CONCLUSIONS}

1. The WF content and the presence of MAPP in composites played an important role on density and mechanical properties.

2. Addition of both WF and MAPP in PP- and rPP-based composites has increased density values.

3. The MAPP presence in both PP- and rPP-based composites provided improved TS and TM values with adding wood flours.

4. Regardless of PT, WF improved both FS and FM values of the composites having MAPP as coupling agent.

5. Overall, the mahogany WF can be utilized in both PP- and rPP-based composites when manufacturing with MAPP as coupling agent.

\section{ACKNOWLEDGMENTS}

Special thanks to graduate students Miss Fatma Bozkurt and Miss Busra Avci for sample manufacturing and testing assistances.

\section{REFERENCES CITED}

Adhikary, K. B., Park, C. B., Islam, M., and Rizvi, G. M. (2011). "Effects of lubricant content on extrusion processing and mechanical properties of wood flour-high- 
density polyethylene composites," Journal of Thermoplastic Composite Materials 24(2), 155-171. DOI: 10.1177/0892705710388590

Anoop, E. V., Jijeesh, C. M., Sindhumathi, C. R., and Jayasree, C. E. (2014). "Wood physical, anatomical and mechanical properties of big leaf mahogany (Swietenia macrophylla) a potential exotic for South India," Research Journal of Agriculture and Forestry Sciences 2(8), 7-13.

ASTM D256 (2000). "Standard test methods for impact resistance of plastics and electrical insulating materials," American Society for Testing and Materials, West Conshohocken, PA.

ASTM D638 (2001). "Standard test methods for tensile properties of plastics," American Society for Testing and Materials, West Conshohocken, PA.

ASTM D790 (2003). "Standard test methods for flexural properties of unreinforced and reinforced plastics and electrical insulating materials," American Society for Testing and Materials, West Conshohocken, PA.

ASTM D792 (2007). "Standard test methods for density and specific gravity (relative density) of plastics by displacement," American Society for Testing and Materials, West Conshohocken, PA.

ASTM D2240 (2010). "Standard test method for rubber property-durometer hardness," American Society for Testing and Materials, West Conshohocken, PA.

Bozkurt, Y., and Erdin, N. (1998). Ticarette Önemli Yabancı A ̆gaçlar, University of İstanbul, Graduate School of Natural and Applied Sciences Publications, İstanbul.

Clemons, C. M. (2010). "Wood flour," in: Functional Fillers for Plastics ( $2^{\text {nd }}$ Ed.), Wiley-VCH, Weinheim, pp. 269-290.

Çavuş, V., and Mengeloğlu, F. (2016). "Utilization of synthetic based mineral filler in wood plastics composite," Journal of Achievements in Materials and Manufacturing Engineering 77(2), 57-63. DOI: 10.5604/17348412.1230098

Çetin, N. S., Özmen, N., Narlığlu, N., and Çavuş, V. (2014). "Effect of bark flour on the mechanical properties of HDPE composites," Journal of Materials Science 1(3), 2332. DOI: $10.12748 /$ uujms.201416497

Ibach, R. E., and Rowell, R. M. (2013). "Lumen modifications," in: Handbook of Wood Chemistry and Wood Composites ( ${ }^{\text {nd }}$ Ed.), R. M. Rowell (ed.), CRC Press, Boca Raton, FL, USA, pp. 599-625.

Karakuş, K., and Mengeloğlu, F. (2016). "Polycaprolactone (PCL) based polymer composites filled wheat straw flour," Kastamonu Universitesi Orman Fakültesi Dergisi 16(1), 264-268.

Kattas, L., Gastrock, F., Levin, I., and Cacciatore, A. (2000). "Plastic Additives in Modern Plastics Handbook," McGraw-Hill, New York, USA.

Klyosov, A. A. (2007). "Wood-plastic Composites," Wiley, Hoboken, NJ, USA.

Kim, J. K., and Pal, K. (2011). "Effect of compatibilizers in WPC composites," in: Recent Advances in the Processing of Wood-Plastic Composites, Springer, Berlin, pp. 103-127.

Lemmens, R. M. H. J. (2005). "Swietenia macrophylla King. Record from Protabase," (http://database.prota.org/search.htm), Accessed on December 27, 2018.

Li, Q., and Matuana, L. M. (2003). "Effectiveness of maleated and acryclic acidfunctionalized polyolefin coupling agents for HDPE-woodflour composites," Journal of Thermoplastic Composite Materials 16, 551-564. DOI: 10.1177/089270503033340 
Li, H., Law, S., and Sain, M. (2004). "Process rheology and mechanical property correlationship of wood flour-polypropylene composites," Journal of Reinforced Plastics and Composite 23(11), 1153-1158. DOI: 10.1177/0731684404035416

López, J. P., Gironès, J., Méndez, J. A., El Mansouri, N.-E., Llop, M., Mutjé, P., and Vilaseca, F. (2012). "Stone-ground wood pulp-reinforced polypropylene composites: water uptake and thermal properties," BioResources 7(4), 5478-5487. DOI: 10.15376/biores.7.4.5478-5487

Mäkinen, H., Saranpää, P., and Linder, S. (2002). "Wood-density variation of Norway spruce in relation to nutrient optimization and fiber dimension." Canadian J. For Res 32, 185-194.

Martikka, O., and Karki, T. (2019). "Promoting recycling of mixed waste polymers in wood-polymer composites using compatibilizers," Recycling 4(1), 6. DOI: 10.3390/recycling4010006

Matuana, L. M., Park, C. P., and Balatinecz, J. J. (1998). “Cell morphology and property relationships of microcellular foamed PVC/Wood-fiber composites," Polymer Engineering and Science 38, 1862-1872. DOI: 10.1002/pen.10356

Mengeloğlu, F., and Çavuş, V. (2019). "Additives used in wood plastic composite manufacturing" in: Research and Reviews in Agriculture, Forestry and Aquaculture Sciences - Summer, Gece Publishing, New York, USA, pp. 49-58.

Mengeloğlu, F., and Karakuş, K. (2012). "Mechanical properties of injection-molded foamed wheat straw filled HDPE biocomposites: The effects of filler loading and coupling agent contents," BioResources 7(3), 3293-3305. DOI: 10.15376/biores.7.3.3293-3305

Mengeloğlu, F., and Karakus, K. (2008). "Some properties of eucalyptus wood flour filled recycled high density polyethylene polymer-composites," Turkish Journal of Agriculture and Forestry 32, 537-546.

Özmen, N., Çetin, N. S., Narlığlu, N., Çavuş, V., and Altuntaş, E. (2014). "Utilisation of MDF waste for wood plastic composites production," University of Süleyman Demirel Faculty of Forestry Journal 15, 65-71.

Rowell, R. M. (2006). "Advances and challenges of wood polymer composites," in: Proceedings of the $8^{\text {th }}$ Pacific Rim Bio-Based Composites Symposium, Kuala Lumpur, Malaysia.

Sharmin, A., Ashaduzzaman, M., and Shamsuzzaman, M. (2015). "Variations of the physical and mechanical wood properties of swietenia macrophylla in mixed and monoculture plantations," International Research Journal of Engineering and Technology (2)5, 692.

Yang, H., Yan, R., Chen, H., Lee D. H., and Zheng, C. (2007). "Characteristics of hemicellulose, cellulose and lignin pyrolysis," Fuel 86, 1781-1788. DOI: 10.1016/j.fuel.2006.12.013

Article submitted: October 30, 2019; Peer review completed: January 13, 2020; Revised version received: January 30, 2020; Accepted: February 2, 2020; Published: February 7, 2020.

DOI: 10.15376/biores.15.2.2227-2236 